\title{
OUR EXPERIENCE WITH LAPAROSCOPIC SLEEVE GASTRECTOMY IN THE THERAPY OF MORBID OBESITY
}

\author{
Koren R, Marko L, Vladovic P. \\ Department of Minimally Invasive Surgery and Endoscopy, F.D. Roosevelt Faculty Hospital with Policlinic, \\ Banska Bystrica, Slovakia
}

\section{A b s tract}

Objective: The purpose of this study is to evaluate the results and experience with Laparoscopic sleeve gastrectomy (LSG) in the treatment of morbid obesity.

Methods: The authors in their retrospective analysis evaluate their 6-years experience with LSG on the Department of Minimally Invasive Surgery and Endoscopy in Banská Bystrica. The study is aimed at the examination of the efficacy of LSG on the weight loss as well as on its effect on the associated diseases after 3, 6, 12 and 24 months after LSG.

Results: The \% Excess Weight Loss (\%EWL) in obese patients 2 years after LSG was $74.4 \%$. There was also regression of diabetes mellitus (DM) in 75\% patients and arterial hypertension in 68.7\% patients after LSG.

Conclusion: Laparoscopic sleeve gastrectomy is a safe and effective method in the case of weight loss as well as in the regression of associated diseases.

Key words: obesity, therapy of obesity, sleeve gastrectomy

\section{INTRODUCTION}

Nowadays obesity is considered a chronic disease with the serious adverse effect on the health of the particular individual. Obesity was declared the global epidemic by WHO because of the constant increasing prevalence and it represents one of the most serious medical problems of the present time. It presents the significant medical, social and economic problem together with the associated diseases and complications the cause of which is also the obesity to some extent.

According to WHO data there is almost a doubled number of the obese people in the year 2008 when we compare it with the year 1980. In 2008 there were $35 \%$ adults above 20 years overweight which is about 1.4 milliard people. Almost 200 million men and almost 300 million women of that number were obese (1). The program IDEA performed in Slovakia in the year 2005 found that nearly every second adult Slovak has an increased volume of the intraabdominal fat. The obesity was found in every third woman (34.7\%) and in every fourth man $(27.0 \%)(2)$.

The principle of the obesity treatment should be prevention however because of the small enlightenment and because of being unaware of the risks resulting from the obesity the number of the obese people is still increasing.

The therapy itself requires a complex access and multidisciplinary cooperation. For the lower grades of obesity there is a dominant therapy a diet, kinesitherapy, pharmacotherapy and cognitive behavioral therapy. In case of the morbid obesity the best results are achieved by the combination with the surgical therapy. Bariatric surgery, ergo the surgical therapy of the obesity treats the obesity not as an aesthetic problem but in the first place as a complex disease causing serious medical complications, it significantly improves the general health state and decreases the risks of morbidity and mortality connected with the

Corresponding a u thor:

Koreň Roman, MD, Department of Minimally Invasive Surgery and Endoscopy, F.D. Roosevelt Faculty Hospital with Policlinic, Banska Bystrica, Slovakia 
obesity. Bariatric operations prolong surviving of the people with the obesity, improve their life quality and reduce medical risks of diabetes mellitus 2 type (DM2T), cardiovascular diseases and cancer $(3,4,5,6)$. Accompanying phenomenon of bariatric operations is not only the weight loss but

also the marked positive effect on the associated metabolic diseases as DM2T and metabolic syndrome, what is even more important $(4,7,8)$. Nowadays we call these operations as bariatric - metabolic in regard of the positive effect of the surgical therapy also on the metabolic diseases.

Bariatric - metabplic operations are divided into:

- restrictive procedures: adjustable gastric band, sleeve gastrectomy, gastric plication

- malabsorptive procedures: biliopancreatic diversion, biliopancreatic diversion with duodenal switch

- combined (hybrid) procedures: gastric bypass

The principle of the restrictive operations is the reduction of the gastric volume. Reduced volume of the stomach causes a decrease of the food intake as already the smaller amount of food makes the feeling of fullness. In case of malabsorptive operations the dominant effect is based on the decrease of the nutrients resorption and the restriction of the food intake is less important. Combined operations make use of the principle of the restriction together with the malabsorption. Malabsorptive and combined operations are often connected with the malnutrition of some nutrients and require a lifelong supplementation of vitamins or minerals $(9,10)$. The consequence of the passage shortening after the malabsorptive operations is the passage acceleration, too (6 and more loose and smelly stools) (3). Negatives of the malabsorptive and combined bariatric operations are the reason for performing the restrictive operations at some departments including ours. Although they have a bit lower effect on the weight loss, they have lower risk of complications and usually do not require lifelong mineral and vitamin supplementation.

In 1978 in the USA Wilkinson proposed a non-adjustable gastric bandage and in 1984 in Sweden Frosell and two years later Kuzmak in the USA designed adjustable gastric bandage in order to reduce the gastric capacity without the need of its resection $(6,11)$. The second one became rather quickly very popular after the year 1992, when it was performed for the first time by Fried in the Czech Republic laparoscopically, especially in Europe and later in the USA. Its advantage is a simplicity and the fact that in case of complications it is fully reversible anatomically and also functionally (12). Weight loss after this operation was and is rather dependent on the patient s cooperation. \% EWL is reported 35-56\%. In case of patient $\mathrm{s}$ noncooperation and infringement of recommended eating habits the patient does not only achieve weight reduction but also can cause the serious complications which often break up with the need of bandage removal.

Another restrictive method is sleeve gastrectomy. It initially represented the first phase of two step biliopancreatic diversion with duodenal switch but because of its favourable results, performing of the second phase - duodenal switch was stopped. Since 2003 the Sleeve gastrectomy has been performed as a single operation (13). Its principle is a removal of $60-80 \%$ of corpus and fundus of the stomach from the side of the greater curvature and the preservation of the antrum $4-6 \mathrm{~cm}$ from the pylorus and the corpus on the side of the lesser curvature. Stomach after the resection has the shape of a sleeve with the volume of 60-180ml. Removed part of the stomach contains also the zone of the production of the hunger hormone ghrelin. Its levels become higher during the common hunger. There is a significant suppression of ghrelin production and its levels decrease markedly after LSG (14) what has a favorable effect when the food intake is decreased. 


\section{MATERIAL AND METHODS}

We analyzed results and our experience gained by performing 54 laparoscopic sleeve gastrectomies from March 2008 until April 2014 on the Department of Minimally Invasive Surgery and Endoscopy of Surgery Clinic of the Slovak Medical University in Banská Bystrica. The average age of all patients in the group was 46.4 years (22-61 years). There were 40 women ( $74 \%$ of the operated patients) and 14 men ( $26 \%$ of the operated patients) in the group. The average weight of the patients in the group before the operation was $134.5 \mathrm{~kg}(92-230 \mathrm{~kg})$. The average height of the patients was $169.8 \mathrm{~cm}(158-185 \mathrm{~cm})$. The average BMI of all patients before the operation was $46.6 \mathrm{~kg} / \mathrm{m}^{2}\left(34.6-67.2 \mathrm{~kg} / \mathrm{m}^{2}\right)$. The waist circumference of the patients before the operation was $130.5 \mathrm{~cm}(105-188 \mathrm{~cm})$ and their average preoperative overweight was $62.4 \mathrm{~kg}(25.6-144.4 \mathrm{~kg})$.

We have also focused on associated diseases related to the obesity when evaluating patient $\mathrm{s}$ history data before the operation. In the group of 54 patients 24 patients (44.4\%) had DM2T or impaired glucose tolerance - 18 patients (33.3 \%) had medicamentous treatment and 6 patients $(11.1 \%)$ had a diabetic diet. 42 patients $(77.8 \%)$ were treated for arterial hypertension, 17 patients $(31.5 \%)$ had hyperlipidemy, 12 patients $(22.2 \%)$ had hepatopathy. 3 male patients (5.5\%) had sleep apnea syndrome and required Continuous positive airway pressure (CPAP) mask for night. 5 female patients $(9.3 \%)$, were taking drugs for depressive disorder. Only one female patient had morbid obesity without associated diseases and 8 patients had associated diseases without any need of medicamentous therapy. None of the patients required proton pump inhibitors (PPI) treatment for Gastroesophageal reflux disease (GERD).

All patients fulfilled the indication criteria for bariatric surgery. 7 patients were indicated for surgery because of Laparoscopic Adjustable Gastric Banding (LAGB) failure and one female patient after repetitive treatment by intragastric balloon ( BIB - intragastric balloon was inserteded two times for 6 months).

We performed the operation using 5 ports with inserted $38 \mathrm{~F}$ calibration orogastric tube. The resection line initiated $5 \mathrm{~cm}$ before the pylorus and ended 1-2 $\mathrm{cm}$ laterally from the angle of His. We used Echelon 60 with blue reloads for resection. We always used water exam to test the resection line tightness. We did not use additional suture on the resection line, we covered it by Surgicel.

The patients after the operation were on the intensive care unit for the first 24 hours after the operation with inserted nasogastric tube. They had an X-ray examination of stomach with a water soluble contrast agent on the first postoperative day. They also drunk a small amount of liquid colored with methylene blue. They started with oral fluid intake (water, tea) in small amounts - totally 300-500 $\mathrm{ml}$ per 24 hours when the X-ray finding was negative and there were no residua in nasogastric tube.

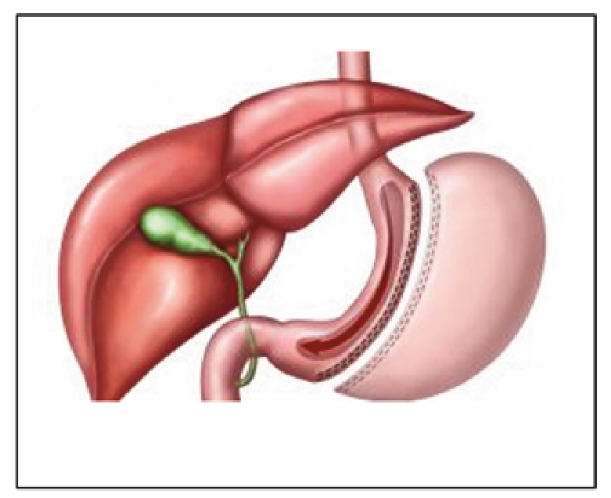

Fig. 1 Sleeve gastrectomy (Source: http://www.gastricsleevecenter.com) 


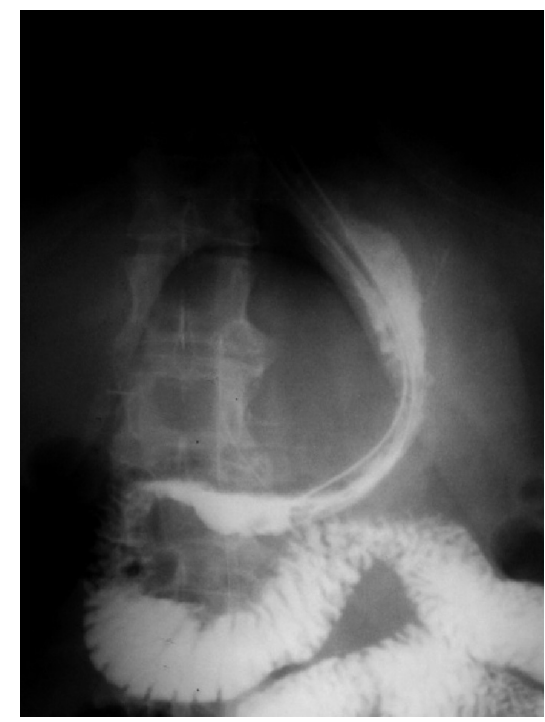

Fig. 2 X-ray examination after LSG. (Source: author s database)

They drank 1000-1500 $\mathrm{ml}$ of water or tea per 24 hours on the second postoperative day. On the third postoperative day they drank liquids in the amount of 2000-2500 ml. From the fourth day the patients ate tepid soups and juices. They were discharged from the hospital on the fifth to seventh postoperative day, the stitches were removed on the tenth postoperative day. They were followed up after 3, 6, 12 months and then annually in the outpatient care.

All patients took part in a personal or a phone interview from April 15th until April 30th, 2014 , for the purpose of our research work. Gained data were added to result database and the actual BMI as well as weight loss , Excess Weight Loss (\%EWL) and excess BMI loss (\%EBMIL) were calculated. The influence of LSG and weight loss on the need of drug administration for DM and arterial hypertension was observed simultaneously.

\section{RESULTS}

The average time of all sleeve gastrectomies at our department was 105 minutes (55-210 min.) The average time of laparoscopic sleeve gastrectomies, without other accessory operations was 88.2 minutes (55 - 150 min.). Concomitant laparoscopic cholecystectomy and LSG was performed six times, Adjustable Gastric Band ( AGB) extraction was a part of LSG five times. We used an average of $7(5-11)$ blue reloads for Echelon $60 \mathrm{~mm}$ for the greater curvature of stomach resection.

We had 5 perioperative complications - once bleeding after splenic injury which was treated conservatively without the need of splenectomy, twice postoperative bleeding which were treated conservatively without the need of reoperation and one patient had a bronchospasm shortly after the operation - he was re-intubated for 24 hours. We have never been forced to convert laparoscopic sleeve gastrectomy to open procedure. In the postoperative period we recorded the resection line dehiscence in 2 patients $(3,7 \%)$ what was the cause of reoperation, one dehiscence was fatal. One patient had wound seroma and one had wound hematoma. 


\section{Results recorded 3 month after LSG}

During the first 3 months the average weight loss was $16 \mathrm{~kg}$ and reduced BMI about 7.5 $\mathrm{kg} / \mathrm{m}^{2}$. Patients after LSG reduced their weight about $16 \%$ and overweight about almost $36 \%$. The lowest weight loss for the first 3 months was $11 \mathrm{~kg}$, \% EWL was $16.2 \%$ and the highest weight loss was 38kg, \%EWL was 74.4\%. During this period 20 patients (58.8\% of the patients) had a nausea and reflux, 15 patients $(44.1 \%)$ needed an administration of PPI. Ten female patients (29.4\%) had an increased hair loss and 3 patients had dysuria.

\section{Results recorded 6 month after LSG}

During the first 6 months the average weight loss was $31.7 \mathrm{~kg}$ and reduced BMI about 11.2 $\mathrm{kg} / \mathrm{m}^{2}$. Patients after LSG reduced their weight about $24.1 \%$ and overweight about $56.2 \%$. The lowest weight loss for the 6 months was $7 \mathrm{~kg}$, \% EWL was $16.2 \%$ and the highest weight loss for 6 months was 53kg, \%EWL was 93.9\%. Out of 34 patients in the group 6 months after the operation 7 patients needed an administration of PPI regularly because of GERD and 8 patients suffered from GERD which was sufficiently cured by a diet or by the occasional administration of PPI. Only 4 female patients had hair loss problems. Other complications did not occur.

\section{Results recorded one year after LSG}

During the first year the average weight loss was $31.7 \mathrm{~kg}$ and reduced BMI about 11.2 $\mathrm{kg} / \mathrm{m}^{2}$. Patients after LSG reduced their weight about 29.8\% and overweight about $68.5 \%$. The lowest weight loss for one year was $17 \mathrm{~kg}$, \% EWL was $57.1 \%$ and the highest weight loss was $63 \mathrm{~kg}$, \%EWL was $111.6 \%$. During this period the waist circumference of the patients reduced about $36.9 \mathrm{~cm}$ on average. One female patient put on weight from the last checkup (after 6 months) about $3 \mathrm{~kg}$ and two patients had the same weight as 6 months after the operation.

Seven patients needed an administration of PPI because of GERD regularly, 4 patients occasionally and the rest of patients did not need PPI therapy. Only one patient had increased hair loss after one year but it was not so intensive any more. Other complications did not occur.

\section{Results recorded 2 years after LSG}

During two years the average weight loss was $44.1 \mathrm{~kg}$ and reduced BMI about 15.2 $\mathrm{kg} / \mathrm{m}^{2}$. Patients after LSG reduced their weight about 33.6\% and overweight about $77.2 \%$. The lowest weight loss for two years was $22 \mathrm{~kg}$, \% EWL was $44.2 \%$ and the highest weight loss was $68 \mathrm{~kg}$, \%EWL was 110.7\%. During this period the waist circumference of the patients reduced about $35 \mathrm{~cm}$ on average. Comparing the weight of the patients one year after the operation and two years after the operation we have already found out less significant weight loss and five patients (4 men and 1 woman) put on weight about $10 \mathrm{~kg}$ on average. One patient put on $33 \mathrm{~kg}$ during 1 year. It was a patient with a lack of discipline. He confessed the fact that he was not on any diet and his eating had no limits. His weight started to increase after 15 months. 6 patients had the same weight after the second year as after the first year and 14 patients had the lower weight after the second year about $8.4 \mathrm{~kg}$ on average.

Five patients 2 years after LSG needed an administration of PPI because of GERD regularly, 6 patients occasionally and the rest did not need PPI therapy. No patient had hair loss. Other complications did not occur.

During the final personal or phone interview we found out that two patients had a weight increase already after one year after the operation about $1-2 \mathrm{~kg}$ but the following year their weight was oscillating $\pm 2 \mathrm{~kg}$. One patient gained $3 \mathrm{~kg}$ on weight after one year but the following year she lost $7 \mathrm{~kg}$. There was an interesting finding of the patient who was not on any checkup and after the operation he was not on any diet. In spite of this his weight decreased in the first year from $165 \mathrm{~kg}$ to $130 \mathrm{~kg}$ but in turn from the $15^{\text {th }}$ month 
it started to increase and 5 years after the operation his weight was about $5 \mathrm{~kg}$ less than before the operation.

Two patients, one man and one woman had a weight loss up to the second year after the operation. Then they started with the administration of corticoids and psychiatric medication because of other diseases and started to put on weight gradually. One of them had the weight 6kg higher 5 years after the operation than he had before LSG.

One patient was losing the weight up to the second year after the operation when she got pregnant. One year after the childbirth she has $12 \mathrm{~kg}$ higher weight than she had 2 years after the operation, however, still it is $10 \mathrm{~kg}$ less than she had before the operation.

All 7 patients who underwent LAGB before LSG, even the female patient after the repeated application of BIB, were more satisfied with LSG than with LAGB or BIB. If they had to decide again they would choose LSG as the first choice.

The patients were questioned how satisfied they were with the operation. 46 patients out of 50, who were more than 3 months after the operation, were very satisfied, some of them expressed a maximal satisfaction and 3 patients were satisfied with the operation. One patient (the one, who was not on a diet and did not undergo the checkups) was partially satisfied. No patient was unsatisfied. All of the questioned patients would surely undergo LSG if they had do decide again. Three patients would like even bigger stomach reduction. A significant weight loss caused a massive overhang of the abdominal skin in 7 patients and 4 patients underwent abdominoplasty for venter pendulum. One patient underwent even the lifting of mastoptosis. One patient needed an administration of Sorbifer because of anaemic syndrome after 6 months after the operation.

\section{Influence of LSG on DM and arterial hypertension in the group of our patients}

We have focused on the influence of LSG and weight loss on the improvement of DM and arterial hypertension within the evaluated parameters. We included 45 patients into the group which we evaluated, they were all patients who were 6 and more months after the operation. 20 patients from this group had diabetes mellitus or impaired glucose tolerance - it was $44 \%$ from all patients. 16 patients (36.5\%) had DM, which was treated with oral antihyperglycemic agents or with insulin, 4 patients had diabetic diet. 6 and more months after the operation, DM was improved in all patients except one male patient who did not respect the therapy of DM. From the group of 16 patients who required treatment of DM before the operation only 4 patients required treatment after the operation, three of them had significantly reduced treatment or started to use oral antihyperglycemic agents instead of insulin. One above mention patient had unchanged treatment. There was a significant DM regression in patients with morbid obesity thanks to LSG. It was in such an extent that $75 \%$ of these patients did not have to use anti-diabetic drugs, they had just diabetic diet.

38 patients in this group had arterial hypertension, what was $84.4 \%$. 32 patients $(71.1 \%$ from the whole group) used antihypertensive drugs, 6 patient had hypertension diet. After LSG, there was a regression of arterial hypertension in 35 patients, the treatment did not change in 3 patients. It was a female patient who regained the weight because of antidepressants and corticoid therapy, a male patient who needed administration of corticoids two years after the operation because of newly diagnosed adrenal disease and a male patient who did not respect treatment. Despite of this, 10 patients from 32 patients treated for arterial hypertension still needed administration of antihypertensive drugs in significantly reduced dose. There was a therapy regression in $68.7 \%$ patients. If we excluded the three above mentioned patients from the group, the therapy regression would be $75.8 \%$. 
Table 1 Weight, BMI, waist circumference and \%EWL changes after 3, 6, 12 and 24 months

\begin{tabular}{|l|c|c|c|c|c|}
\hline TOGETHER & $\begin{array}{c}\text { before } \\
\text { operation }\end{array}$ & $\begin{array}{c}\text { after 3 } \\
\text { months }\end{array}$ & $\begin{array}{c}\text { after 6 } \\
\text { months }\end{array}$ & $\begin{array}{c}\text { after one } \\
\text { year }\end{array}$ & $\begin{array}{c}\text { after two } \\
\text { years }\end{array}$ \\
\hline Average weight (kg) & 134.5 & 114.6 & 99.8 & 93.4 & 88.3 \\
\hline Weight loss (kg) & - & 21.8 & 31.9 & 39.5 & 42.4 \\
\hline Average BMI (kg/m2) & 46.6 & 39.9 & 34.4 & 32.2 & 30.5 \\
\hline Average waist circumference (cm) & 130.47 & 117.4 & 108.4 & 100.4 & 93.7 \\
\hline \% EWL & - & 35.9 & 56.2 & 68.5 & 74.4 \\
\hline
\end{tabular}

\section{DISCUSSION}

Couple of years ago the laparoscopic adjustable gastric bandage LAGB was in primus in bariatric surgery in many workplaces. It used to be the most used method in Europe and in the USA it is even nowadays the second most often performed bariatric method (15).

This quite simple bariatric method with the relatively good results, as the excess weight loss after 6 months 25-48\% and after 12 months 31-52\% (16), has also its complications that are not serious but rather frequent. These complications often required reoperation or the removal of the bandage. Patients with lack of discipline often caused to themselves dilatations of created pouch. There were migrations and slippages of the band, stenosis causing vomiting and gastric wall erosions caused by band after adjusting. There were also wound infections, intraabdominal infections and adjustable chambers and bands intolerances. The total number of complications after LAGB reached almost 30\%, while 12-20\% patients after LAGB required another operation because of complications (15, 17, 18, 19). Since 2003 laparoscopic sleeve gastrectomy has been used as a single bariatric operation. This method is getting more popularity thanks to its good results and low percentage of total complications, although the number of serious complications was higher than with LAGB. Comparing to former restrictive bariatric method LSG has \%EWL after 12 months 80.9\% (16) and average number of complications 12.1\% (20). Most complications after LSG occur in perioperative period, in contrast with LAGB.

We can confirm the effectiveness of LSG based on our own experience. Because of LSG there was an excess weight loss in obese patients $56.2 \% 6$ months after operation and $68.5 \% 12$ months after the operation in the group of our patients. Our results are comparable with the results of other departments - see table 2. The results of Korean authors who have $83.3 \%$ EWL already one year after the operation are remarkable (20).

If we focus on the effectiveness of LSG on the associated diseases regression our results are in accordance with literary data. There is an improvement of DM and arterial hypertension in almost all patients. According to literary data the cure rate of DM is $66-80 \%$, we had $75 \%$ cure rate. In case of arterial hypertension the cure rate is $71.7 \%$, we had $68.7 \%$ cure rate $(16,20)$.

The average operation time from different authors is 49 - 111 minutes (20). In our group of patients we had the average operation time 105 minutes in all patients. When we performed LSG without other concomitant operations the average operation time was 88.2 minutes. The average length of hospitalization after LSG is 4,4 days. Patients who underwent LSG at our department stayed in the hospital 6.9 days at average. 
Table 2 Excess weight loss after LSG

\begin{tabular}{|l|c|c|}
\hline$\% E W L$ & 6 months after LSG & 12 months after LSG \\
\hline Mongol et al. & - & 51 \\
\hline Langer et al. & 61 & 51.8 \\
\hline Wang et al. & 50.6 & 58.1 \\
\hline Fogel et al. & - & 52.8 \\
\hline Uffort et al. & 51.7 & 83.3 \\
\hline Han et al. & - & - \\
\hline Roa et al. & 53 & - \\
\hline Himpens & 66 & 68.5 \\
\hline Dept. Banska Bystrica & 56.2 & - \\
\hline
\end{tabular}

LSG has twice more frequent perioperative complications than LAGB, they occur in $12.1 \%$ cases. Paradoxically, the average mortality after LAGB is $0.47 \%$ and $0.3 \%$ after LSG (20). We had one demise in our group of patients, what is $1.85 \%$ from the total number of 54 patients. Total perioperative complications were in $16.6 \%$ cases. The presence of the leak from the dehiscence of the resection line is in $1.17 \%$ cases $(0 \%-7 \%)(20,21)$.

The staple line leak can occur in two forms. The staple line leak Type I, also called subclinical, is controlled by the inserted drain or created fistula. The staple line leak Type II is a clinical leak which demonstrates by the diffuse spread of the contrast agent into the abdominal cavity.

Once the leak is diagnosed, it is very important to monitor the clinical condition of the patient and the wastes into the drain. X-ray control examinations with contrast agent should be performed routinely. The combination of febrility, tachycardia and tachypnea has the highest sensitivity 58.3\% and specificity $99.75 \%$ for the diagnosis of anastomosis leak (22). The reliability of X-ray examination with a contrast agent is controversial. We had the resection line leak after LSG in two cases in our group of patients. In both cases the X-ray examination with contrast agent was negative, it was a CT examination which proved the leak. Simon et al. mention the similar experience, they use CT examination to diagnose a leak and add endoscopic examination. Simon et al perform toilet and drainage by laparotomy or laparoscopy and insert covered Hanarostent with anti-reflux valve under direct endoscopic control. The average stent treatment duration is 6 weeks (21).

Bleeding is another serious perioperative complication. The most common sources of bleeding are the cut vessels on the greater curvature of stomach, injured spleen or resection line. The serious bleeding during LSG can occur in average $3.6 \%$ cases, some authors mention higher rates - $14.3 \%-15.8 \%(20)$. We had one perioperative bleeding from spleen without the need of splenectomy and two bleedings in postoperative period treated conservatively without the need of reoperation in our group of patients. We had no gastric stenosis with passage disorders, nor other complications.

Based on our results we can clearly confirm that laparoscopic sleeve gastrectomy for morbid obesity is a safe and highly effective method not just for weight reduction but also for the regression of associated metabolic diseases. It is also a suitable alternative for less disciplined patients. In case of the failure it is the first phase of biliopancreatic diversion with duodenal switch which is performed in two steps. 


\section{REFERENCES}

1. Obesity and overweight. Fact sheet Nr.311[online]. Geneve : WHO, March 2013]. Dostupné na internete: <http://www.who.int/mediacentre/ factsheets/ fs311/en/>.

2. DUKÁT A, LIETAVA K, KRAHULEC B et al. IDEA - prvé výsledky o prevalencii abdominálnej obezity na Slovensku. Via practica 2006; 3 (12): 554-558.

3. DOLEŽALOVÁ K et al. Bariatrická chirurgie a primární péče. Praha : Axonite CZ; 2012.

4. KASHYAP SR., GATMAITAN P, BRETHAUER S. et al. Bariatric surgery for type 2 diabetes: weighing the impact for obese patients. Cleveland Clinic journal of medicine 2010; 77 (7): 468-476.

5. RUBINO F. From bariatric to metabolic surgery: definition of a new discipline and implications for clinical practice. Current atherosclerosis reports 2013; 15 (12): 369.

6. FRIED M. a kol. Bariatrická a metabolická chirurgie: nové postupy v léčbě obezity a metabolických poruch. Praha: Mladá fronta; 2011.

7. GLOY VL, BRIEL M, BHATT DL et al. Bariatric surgery versus non-surgical treatment for obesity: a systematic review and meta-analysis of randomised controlled trials. BMJ:British medical journal 2013; p. 347 : f5934.

8. BUCHWALD H, ESTOK R, FAHRBACH K et al. Weight and type 2 diabetes after bariatric surgery: systematic review and meta-analysis. American journal of medicine 2009; 122 (3): 248-256.

9. MATRANA MR, DAVIS WE. Vitamin deficiency after gastric bypass surgery: a review. Southern medical journal 2009; $102(10): 1025-1031$.

10. KRAHULEC B et al. Klinická obezitológia. Brno: Facta Medica; 2013.

11. MÜLLEROVÁ D et al. Obezita - prevence a léčba. Praha : Mladá fronta; 2009.

12. KASALICKÝ M. Tubulizace žaludku: [chirurgická léčba obezity]. Praha : Triton; 2007.

13. MARKO L. Minimálne invazivna chirurgia a endoskopia. Banská Bystrica: Marko BB; 2012.

14. KOTIDIS EV, KOLIAKOS GG, BALTZOPOULOS VG et al. Serum ghrelin, leptin and adiponectin levels before and after weight loss: comparison of three methods of treatment-a prospective study. Obesity surgery 2006; 16 (11): 1425-1432.

15. GAGNON LE, KARWACKI SHEFF EJ. Outcomes and complications after bariatric surgery. American journal of nursing 2012; 112 (9) : 26-36.

16. WANG S, LI P, SUN XF. Comparison between laparoscopic sleeve gastrectomy and laparoscopic adjustable gastric banding for morbid obesity: a meta-analysis. Obesity surgery 2013; 23(7):980-986.

17. BELLANGER DE, GREENWAY FL. Laparoscopic sleeve gastrectomy, 529 cases without a leak: short-term results and technical considerations. Obesity surgery 2011; 21 (2): 146-150.

18. ZUEGEL NP, LANG RA, HÜTTL TP et al. Complications and outcome after laparoscopic bariatric surgery: LAGB versus LRYGB. Langenbeck's archives of surgery 2012; 397 (8): 1235-1241.

19. EID I, BIRCH DW, SHARMA AM. Complications associated with adjustable gastric banding for morbid obesity: a surgeon's guides. Canadian jouranl of surgery 2011; 54 (1): 61-66.

20. SHI X, KARMALI S, SHARMA AM et al. A review of laparoscopic sleeve gastrectomy for morbid obesity. Obesity surgery 2010; 20 (8): 1171-1177.

21. SIMON F, SICILIANO I, GILLET A et al. Gastric leak after laparoscopic sleeve gastrectomy: early covered selfexpandable stent reduces healing time. Obesity surgery 2013; 23 (5): 687-692.

22. SARKHOSH K, BIRCH DW, SHARMA A et al. Complications associated with laparoscopic sleeve gastrectomy for morbid obesity: a surgeon's guide. Canadian journal of surgery 2013; 56 (5): 347-352.

Received: July,9,2014

Accepted: August,14,2014 